\title{
Do photographic images of pain improve communication during pain consultations?
}

\author{
Deborah Padfield PhD ${ }^{1}$, Joanna M Zakrzewska MD FDSRCS FFDRCSI FFPMRCA FHEA², \\ Amanda C de C Williams PhD CPsychol ${ }^{3}$
}

D Padfield, JM Zakrzewska, AC de C Williams. Do photographic images of pain improve communication during pain consultations? Pain Res Manag 2015;20(3):123-128.

BACKGROUND: Visual images may facilitate the communication of pain during consultations.

OBJECTIVES: To assess whether photographic images of pain enrich the content and/or process of pain consultation by comparing patients' and clinicians' ratings of the consultation experience.

METHODS: Photographic images of pain previously co-created by patients with a photographer were provided to new patients attending pain clinic consultations. Seventeen patients selected and used images that best expressed their pain and were compared with 21 patients who were not shown images. Ten clinicians conducted assessments in each condition. After consultation, patients and clinicians completed ratings of aspects of communication and, when images were used, how they influenced the consultation.

RESULTS: The majority of both patients and clinicians reported that images enhanced the consultation. Ratings of communication were generally high, with no differences between those with and without images (with the exception of confidence in treatment plan, which was rated more highly in the image group). However, patients' and clinicians' ratings of communication were inversely related only in consultations with images. Methodological shortcomings may underlie the present findings of no difference. It is also possible that using images raised patients' and clinicians' expectations and encouraged emotional disclosure, in response to which clinicians were dissatisfied with their performance.

CONCLUSIONS: Using images in clinical encounters did not have a negative impact on the consultation, nor did it improve communication or satisfaction. These findings will inform future analysis of behaviour in the video-recorded consultations.

Key Words: Art; Doctor-patient interaction; Emotion; Narrative

\section{Les images photographiques de la douleur améliorent-elles la communication pendant les consultations sur la douleur?}

HISTORIQUE : Des images visuelles faciliteraient la communication de la douleur pendant les consultations.

OBJECTIFS : Évaluer si des images photographiques de la douleur enrichissent le contenu ou le processus des consultations sur la douleur en comparant l'évaluation de l'expérience de consultation des patients à celle des cliniciens.

MÉTHODOLOGIE : De nouveaux patients ont reçu des images photographiques de la douleur, déjà créées conjointement par des patients et un photographe, lors de leurs consultations dans une clinique de la douleur. Dix-sept patients, qui ont sélectionné et utilisé les images qui exprimaient le mieux leur douleur, ont été comparés à 21 patients qui n'avaient pas vu ces images. Dix cliniciens ont effectué des évaluations avec et sans images. Après la consultation, les patients et les cliniciens ont évalué les aspects de la communication et, lorsque des images avaient été utilisées, leur influence sur la consultation.

RÉSULTATS : La majorité des patients et des cliniciens ont déclaré que les images amélioraient la consultation. L'évaluation de la communication était généralement élevée, sans comporter de différences entre le groupe ayant eu des images et celui n'en ayant pas eu (à l'exception de la confiance envers le plan thérapeutique, qui a obtenu une meilleure note dans le groupe ayant utilisé les images). L'évaluation de la communication par les patients était inversement proportionnelle à celle des cliniciens seulement dans les consultations comportant des images. Des problèmes méthodologiques sous-tendent peut-être l'absence de différences. Il se peut également que les images aient accru les attentes des patients et des cliniciens et favorisé la divulgation des émotions, rendant les cliniciens insatisfaits de leur performance.

CONCLUSIONS : Les images utilisées lors de rencontres cliniques n'ont pas d'effets négatifs sur la consultation, mais n'améliorent ni la communication ni la satisfaction. Les résultats attesteront l'analyse des comportements lors des consultations vidéo-enregistrées.

Unlike the many examples of therapeutic creation of visual images of pain (16-18), this is, to our knowledge, the first project to introduce photographic images of pain during pain consultations $(2,19)$ using images co-created by a trained artist and individuals with chronic pain. The resulting work was described (20) as marking a radical disjuncture in representations of pain and their therapeutic use, and reviews in nursing and medical journals commented on their communicative power and promise of clinical utility (21-25).

Imagery can be a vehicle for sharing and conveying information or experience of pain not fully captured in language $(1,13,16)$; the use of images, and their ambiguity, can encourage emotional expression and personal disclosure. This was evident in the narratives accompanying co-created images of pain $(2,26)$ that made substantial use of firstperson pronouns and emotions (1), possibly revealing aspects of the resentational drawings $(11-13)$ and existing images $(14)$
improve clinicians' understanding of patients' pain $(14,15)$.

${ }^{1}$ Slade School of Fine Art, University College London; ${ }^{2}$ Consultant and Facial Pain Unit Lead, Eastman Dental Hospital, UCLH NHS

Foundation Trust; ${ }^{3}$ Research Dept of Clinical, Educational 83 Health Psychology, University College London, London, United Kingdom Correspondence: Dr Amanda C de C Williams, Research Dept of Clinical, Educational $\mathcal{E}$ Health Psychology,

University College London, Gower St, London WC1E 6BT, United Kingdom. Telephone 44-2076791608, fax 44-2079161989,

e-mail amanda.williams@ucl.ac.uk

OPEN $\bigcirc$ ACCESS

This open-access article is distributed under the terms of the Creative Commons Attribution Non-Commercial License (CC BY-NC) (http:// creativecommons.org/licenses/by-nc/4.0/), which permits reuse, distribution and reproduction of the article, provided that the original work is properly cited and the reuse is restricted to noncommercial purposes. For commercial reuse, contact support@pulsus.com 

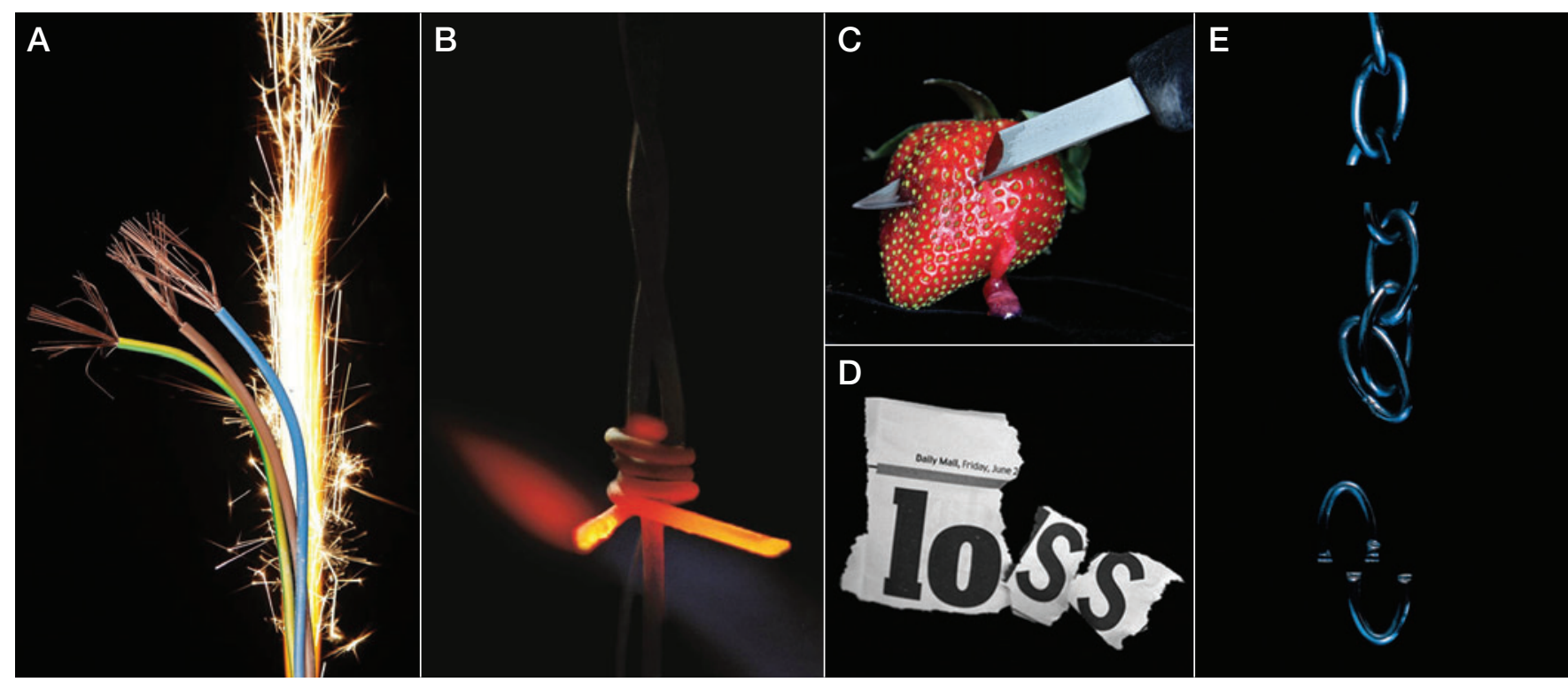

Figure 1) A Image of pain co-created by Deborah Padfield with Chandrakant Khoda from the series Face2Face (c) Deborah Padfield; B Image of pain cocreated by Deborah Padfield with Linda Sinfield from the series Perceptions of Pain (C) Deborah Padfield; C Image of pain co-created by Deborah Padfield with Alison Glenn from the series Face2Face (C) Deborah Padfield; D Image of pain co-created by Deborah Padfield with Liz Aldous from the series Face2Face (C) Deborah Padfield; E Image of pain co-created by Deborah Padfield with John Pates from the series Perceptions of Pain (C) Deborah Padfield

individual's relationship to his or her pain that would not otherwise emerge. Photographs can create a distance between the experience represented and the emotions elicited in those who view it (27-29), accessing less conscious and less articulated aspects. It could also be that such expression facilitates discussion and negotiation between clinician and patient toward a shared understanding, a contrast with the observed tendency of both clinician and patient to speak but not to listen (6).

To investigate whether photographic images of pain (not generated by the patients in the consultations) could enrich the content and/or process of pain consultation, we compared patients' and clinicians' ratings of the consultation experience (26), drawing on models of visual image as narrative (30). We expected that the use of images by patients would give them greater control over the content of the consultation (31), in part by encouraging emotional expression and disclosure. We predicted that when comparing patient and clinician ratings of consultations with and without images, the use of images in consultations would be associated with higher ratings of the consultation content and process, by patient and by clinician, and better agreement of patient and clinician ratings of content and process of the consultation.

\section{METHODS}

The study received ethics approval and was registered (NIHR CRN Clinical Research Portfolio ID no 7451). It was performed with particular attention to avoiding disruption of the clinical assessment during which data were collected.

Photographs were co-created by the first author (DP) with patients on the waiting list for treatment for varied chronic facial pain; the methodology is described in Padfield $(26,32)$. Photographs taken by the artist in collaboration with the individual experiencing pain were subsequently reviewed on a computer, and the patient and artist selected some images for modification, again as a collaboration, to express as clearly as possible the patient's experience of her or his pain. A selection of these photographs was integrated with a selection of images from an earlier project (produced with patients experiencing musculoskeletal pain $[2,33])$ to create a set of 54 'pain cards'. Selection for the final set was made using data from the earlier study, patient and public responses from exhibitions in hospitals and galleries, and in consultation with clinicians. The images were reproduced as laminated pain cards measuring $142 \mathrm{~mm} \times 105 \mathrm{~mm}$ so that they could be easily handled without damage. Predominantly, the photographs feature objects as metaphors for pain (eg, sparks between electrical wires, or hot or sharp materials or objects; Figures 1A, 1B and $1 \mathrm{C}$ ); several depict pain located on the body; and some are more symbolic, abstract and ambiguous, enabling projection of varied emotions onto the image, which would not necessarily be the same for any two viewers. Some images were both metaphorical and abstract; even apparently literal images, such as barbed wire, can have associations such as torture (Amnesty International logo, www. amnesty.org.uk/) that may be conveyed intentionally or unintentionally as part of the experience of pain (Figure 1B).

\section{Participants}

Patients $>18$ years of age and awaiting a first assessment for chronic pain in a university hospital-based specialist pain clinic were invited to participate if they were able to give consent. Patients on the waiting list for pain management treatment (including surgery when relevant) from the clinics of participating specialists were sent invitation letters to participate, along with information sheets and consent forms. Those who were interested were then contacted by the artist to answer any further questions and asked if they would be willing for their assessment to be videotaped. Those who agreed were scheduled for an appointment with the relevant health care professional. None of the patients recruited to this part of the study had participated in the earlier project to create the photographs.

Because production of the photographs was still in process, patients in the first round did not use images, and in the second round were provided with images to use. Apart from this difference, the referral processes, the clinicians and all other aspects of the appointment remained constant. Most pain clinicians saw two patients in each phase. Data from all participants was anonymized and stored separately from the clinical notes.

\section{Procedure}

Each patient was seen only once, but 10 health care professionals saw, on average, two patients from each group. For the with-image group, patients were provided with the 54 image cards approximately $20 \mathrm{~min}$ before their appointment time. They were asked to look through them 
TABLE 1

Patient and clinician ratings of consultations

\begin{tabular}{|c|c|c|}
\hline Patient ratings* & Without images $(n=21)$ & With images $(n=17)$ \\
\hline How well do you feel you were able to communicate your experience of pain? & $5.26 \pm 0.97$ & $5.18 \pm 1.01$ \\
\hline How would you rate your clinician's understanding of your pain following this consultation? & $5.45 \pm 1.00$ & $5.71 \pm 0.59$ \\
\hline How would you rate your rapport with your clinician during this consultation? & $5.48 \pm 0.98$ & $5.77 \pm 0.56$ \\
\hline $\begin{array}{l}\text { How successful was the consultation in arriving at a useful/appropriate treatment/management } \\
\text { decision for the way forward? }\end{array}$ & $5.15 \pm 1.09$ & $5.77 \pm 0.44$ \\
\hline How confident are you in the treatment plan above? & $4.81 \pm 1.17$ & $5.41 \pm 0.71$ \\
\hline Overall how would you rate your satisfaction with this consultation? & $5.31 \pm 1.17$ & $5.59 \pm 0.51$ \\
\hline Mean of ratings above & $5.25 \pm 0.95$ & $5.60 \pm 0.44$ \\
\hline Did you gain an understanding of any aspects of your pain experience you did not have before? ${ }^{\dagger}$ & $0.55 \pm 0.51$ & $0.59 \pm 0.51$ \\
\hline \multicolumn{3}{|l|}{ Clinician ratings* } \\
\hline How would you rate your understanding of your patient's pain following this consultation? & $4.74 \pm 0.79$ & $4.88 \pm 0.67$ \\
\hline How well do you think your patient felt his/her pain was understood? & $4.53 \pm 0.77$ & $4.56 \pm 0.70$ \\
\hline How would you rate your rapport with your patient? & $5.06 \pm 0.64$ & $4.82 \pm 0.39$ \\
\hline $\begin{array}{l}\text { How successful was the consultation in arriving at a useful/appropriate treatment/management } \\
\text { decision for the way forward? }\end{array}$ & $4.94 \pm 0.94$ & $4.85 \pm 0.55$ \\
\hline How confident are you that the patient will adhere to the above? & $4.72 \pm 1.07$ & $4.77 \pm 0.56$ \\
\hline Overall how would you rate your satisfaction with this consultation? & $4.22 \pm 1.05$ & $4.88 \pm 0.49$ \\
\hline Did you gain an understanding of any aspects of your patient's experience you did not have before? ${ }^{\dagger}$ & - & $0.65 \pm 0.49$ \\
\hline
\end{tabular}

Data presented as mean $\pm S D$. * 1 = poor, $6=$ excellent; ${ }^{\dagger}$ Yes $=1$, no $=0$

and select those that they believed related to their pain and/or resonated with their experience of pain to take into the consultation, and to use them if and when they chose during the consultation. The clinician was also free to refer to the images chosen and brought to the consultation by the patient.

Immediately after the consultations in both phases, clinicians and patients separately completed evaluation forms, returning them in sealed envelopes. Patients were presented with these forms by research staff, not by the clinicians. Participants in both groups reported their age and sex; patients also reported the duration of pain, and clinicians their profession and years of practice. Both patients and clinicians completed ratings of communication of pain, clinician's understanding of pain/ estimate of patient's feeling of being understood, rapport, success in arriving at treatment/management decision, confidence in the treatment plan/estimate of the likelihood of patient's adherence to treatment plan, and overall satisfaction with consultation (all 1 = poor, $6=$ excellent) (Table 1); and whether the patient gained new understanding of pain (yes $=1$, no $=0$ ). For the group with images, both patients and clinicians answered questions on how many images were referred to during consultation; whether the images facilitated or enhanced/made no difference to/hindered the consultation; whether using images resulted in changes to content or manner of consultation (yes $=1$, no $=0$ ); and whether images guided the consultation (yes $=1$, no $=0$ ).

\section{RESULTS}

Forty-two patients agreed to participate and were scheduled for an appointment; however, one patient in the first phase and three in the second did not attend their appointments. Patients were unaware of whether they would be using images until they arrived for their appointments in both phases. Thirty-eight patients participated (17 with images and 21 without). Fourteen women and seven men were assessed without the use of images, and 10 women and seven men with the use of images. The largest proportion (42\%) of patients were between 41 and 60 years of age; $29 \%$ were $>60$ years of age, $26 \%$ were between 26 and 40 years of age, and one was $<25$ years of age. Their chronic pain had lasted a median of nine years (interquartile range three to 15 years), with three patients missing data.

Eleven clinicians (six men and five women) participated in the study. Seven were pain specialists; there was also one surgeon, one neurologist, one pain psychologist and one pain physiotherapist. The median number of years in practice was 19 (range three to 36 years). Clinicians completed two, three or four consultations each (a total of 38). Two clinicians performed one consultation without images, eight performed two and one performed three. One clinician performed no consultations with images because she left the hospital before round 2; three performed one consultation with images because their second patient did not attend; and seven performed two consultations with images. There were no biases in allocation to assessments with and without images according to patient sex, clinician sex or patient pain duration.

The mean $( \pm \mathrm{SD})$ duration of the consultation (recorded) was $61 \pm 18$ min (minimum 17 min, maximum $95 \mathrm{~min}$ ). The mean consultation time without images was $65 \pm 19 \mathrm{~min}$, and with images was $59 \pm 16$ min (no significant difference: $\mathrm{t}=0.55, \mathrm{P}>0.5$ ). All 17 patients offered images selected at least two (maximum 14 images; median six images). The mean time spent on images was $4 \min 45 \mathrm{~s} \pm 2 \min 28 \mathrm{~s}$ (range $1 \mathrm{~min} 16 \mathrm{~s}$ to $10 \mathrm{~min} 22 \mathrm{~s}$ ). There was no relationship between the number of images and the time spent on them during the consultation $(r=0.021 ; \mathrm{P}>0.5)$, nor between the number of images and the overall length of the consultation $(r=0.145 ; \mathrm{P}>0.5)$.

\section{Patient experience of consultation and using images}

Patient ratings of the quality of assessments were strongly skewed toward higher values with no differences between the assessments with and without images (Table 1). Overall satisfaction, clinician understanding of pain, and rapport with clinician were both rated a median of 6 with and without images; 'How well can you communicate your pain?' was rated a median 6 without images and 5 with images; success in arriving at a treatment plan was rated a median of 5.5 without images and 6 with, and confidence in the treatment plan was rated 5 without images and 6 with images. The last comparison approached statistical significance (Mann-Whitney $\mathrm{U}=244.5 ; \mathrm{P}=0.052$ ).

Thirteen of the 15 patients (87\%) who answered those items stated that using images enhanced or facilitated the consultation; eight said that it changed the content and six that it did not; seven that it changed the manner of the consultation and six that it did not; but only four agreed that images guided the consultation, and seven reported that they did not. Patients appear to have found these latter questions difficult to answer because there were many more missing values than in other sections. 


\begin{tabular}{|c|c|c|c|c|c|c|c|c|c|c|c|c|c|}
\hline \multirow{2}{*}{ Patient ratings } & \multicolumn{13}{|c|}{ Clinician ratings } \\
\hline & \multicolumn{2}{|c|}{$\begin{array}{l}\text { Understanding } \\
\text { patient's pain }\end{array}$} & \multicolumn{2}{|c|}{$\begin{array}{c}\text { Patient felt pain } \\
\text { understood }\end{array}$} & \multicolumn{2}{|c|}{$\begin{array}{c}\text { Rapport with } \\
\text { patient }\end{array}$} & \multicolumn{2}{|c|}{$\begin{array}{c}\text { Successful } \\
\text { arriving at treat- } \\
\text { ment decision }\end{array}$} & \multicolumn{2}{|c|}{$\begin{array}{c}\text { Confidence in } \\
\text { patient adherence }\end{array}$} & \multicolumn{2}{|c|}{$\begin{array}{c}\text { Overall } \\
\text { satisfaction }\end{array}$} & $\begin{array}{c}\text { New understand } \\
\text { ing of patient's } \\
\text { experience }\end{array}$ \\
\hline Communicating pain & -0.32 & 0.23 & -0.24 & -0.13 & 0.13 & -0.05 & -0.34 & -0.37 & -0.36 & -0.38 & -0.11 & 0.07 & -0.35 \\
\hline $\begin{array}{l}\text { Clinician understanding } \\
\text { of pain }\end{array}$ & 0.02 & -0.08 & 0.11 & 0.02 & 0.19 & 0.09 & -0.05 & 0.34 & -0.02 & -0.53 & 0.28 & -0.15 & -0.41 \\
\hline $\begin{array}{l}\text { Successful arriving at } \\
\text { treatment decision }\end{array}$ & -0.12 & -0.26 & -0.04 & 0.05 & -0.04 & 0.11 & 0.14 & 0.13 & 0.09 & -0.25 & 0.25 & -0.15 & -0.41 \\
\hline $\begin{array}{l}\text { Confidence in treatment } \\
\text { plan }\end{array}$ & -0.01 & -0.27 & 0.13 & 0.12 & 0.01 & 0.06 & 0.37 & 0.11 & 0.32 & -0.55 & 0.42 & -0.04 & -0.53 \\
\hline Overall satisfaction & 0.19 & -0.29 & 0.12 & -0.13 & 0.07 & -0.02 & 0.23 & 0.06 & 0.13 & -0.55 & 0.24 & -0.44 & -0.55 \\
\hline New understanding & -0.09 & -0.19 & -0.29 & 0.14 & -0.16 & 0.24 & 0.15 & 0.07 & -0.05 & -0.34 & 0.02 & -0.20 & -0.62 \\
\hline
\end{tabular}

Bold numbers indicate statistical significance (ie, $P<0.05)$. + With images; - Without images

\section{Clinician experience of consultation and using images}

Clinician ratings (Table 1) of overall satisfaction, how well they understood the patient's pain, how well the patient felt understood, rapport with the patient, success in arriving at a treatment decision and confidence in that decision were combined within conditions, such that each clinician had a mean score for each of these without images and with images. All of these variables were rated a median of 5 with and without images; thus, no tests were run for differences.

Clinicians' feedback on consultations with images were generally positive: eight clinicians (13 consultations) responded that using images enhanced or facilitated the consultation, while two agreed that it did for one patient but not for another. They were more equivocal about what the differences were: five reported that it changed the content of consultations, four that it did not and one gave different responses for the two patients; six reported that it changed the manner of the consultation, three that it did not and one gave different responses for the two patients.

\section{Relationship of patients' and clinicians' ratings from same consultation}

Comparing patients' and clinicians' ratings of understanding of pain, rapport and satisfaction within consultations revealed no differences (medians); however, patients in the group with images were significantly more positive than clinicians for one aspect: confidence in treatment (patients, median = 6; clinicians, median = 5; Mann-Whitney $U=181.5, P=0.033$ ).

Analysis of correlations among patient and clinician ratings (Table 2) revealed no significant relationships within the group without images. In contrast, there were several associations in the group with images, but all in the opposite direction to that expected: higher patient ratings were associated with lower clinician ratings, and lower patient ratings with higher clinician ratings. These associations were: patient and clinician ratings of gaining new understanding of pain $(\mathrm{r}=-0.618 ; \mathrm{P}=0.008)$; clinician ratings of gaining new understanding and patient overall satisfaction $(\mathrm{r}=-0.545$; $\mathrm{P}=0.024)$; clinician ratings of gaining new understanding and patient confidence in treatment plan $(\mathrm{r}=-0.534 ; \mathrm{P}=0.027)$; clinician confidence in treatment adherence by the patient and patient confidence in treatment plan $(r=-0.546 ; P=0.035)$; patient overall satisfaction and clinician confidence in treatment adherence $(r=-0.561 ; \mathrm{P}=0.033)$; and patient ratings of how well the clinician understood pain and clinician confidence in treatment adherence $(\mathrm{r}=-0.525 ; \mathrm{P}=0.044)$. Strict correction (such as Bonferroni) for multiple comparisons would require $\mathrm{P}<0.001$, but because the present study was exploratory, this was not applied.

Number and type of images used and clinician and patient ratings of consultation

Clinician ratings of the consultation were tested for a relationship with the number of images used: the only significant relationship, which was in a negative direction, was that more images were weakly associated with lower clinician satisfaction $(\rho=-0.498 ; P=0.042)$. However, there was no relationship between clinician ratings of the consultation and the time spent on images (all $\rho<0.35$; all $\mathrm{P}>0.1$ ). Comparison of number of images with patient ratings of the consultation revealed no significant relationships.

\section{DISCUSSION}

At the level of self-reported ratings, we largely failed to find the predicted benefits of images for patients or for doctors, and we were puzzled by findings that implied that what benefited the patient caused problems for the clinician and vice versa. Clinicians, who directly compared consultations with and without images, almost all agreed with the statement that using images enhanced the consultation; however, their ratings of consultation content and process did not differ significantly. Patients, in contrast, had only one consultation, with or without images; the only difference between these sets was a nearly significant difference in favour of using images for confidence in the treatment plan. These results were both surprising and somewhat disappointing: there was scant evidence from statistical comparison of responses of improved communication or understanding between patient and clinician from either point of view.

There are several possible explanations. First, consultations were generally rated highly by patients, and rating scales lacked variance and, therefore, also lacked sensitivity to all but large differences. Second, it may be that using images changed the consultation in ways that were not sampled by our questions, such as by raising clinicians' expectations of sharing patients' emotional meanings, thereby lowering ratings of performance against this ideal. This explanation is supported by the consistent inverse relationships between patient and clinician ratings in the consultations with images, and also by the slightly lower clinician satisfaction when more images were used in the consultation, as though using the images was a demanding experience.

Third, consultations with images may have provoked changes in verbal and nonverbal behaviour not detectable at a quantitative level but which may emerge as qualitative differences: early inspection of the consultation videos reveals enriched emotional language and a more equal dialogue (34), consistent with earlier work using images in consultations $(19,32)$, and as advocated to improve communication $(35,36)$. Analysis of behavioural and linguistic differences $(1,37)$ is in progress. Given the widespread expectation in pain $(4,38)$ and, more widely, in medicine (39), that good assessment must include a psychosocial component, it would be unfortunate but important to know if material that facilitates this for the patient also negatively affects the clinician.

Narrative medicine (40-42) has been proposed as a way of eliciting personal narrative within the consultation, as the images were intended to do, but has been little evaluated by patients. It may be that images 
encouraged patients' narrative in a validating way, without extending to feeling fully understood by the clinician (40). Narrative methods can complement rather than substitute for standard assessments $(31,38,43)$, but it is not clear whether describing the pain in greater depth necessarily leads to better mutual understanding between patient and clinician, or whether it raises expectations of understanding in the patient without meeting the clinician's information needs. Photography was described by Berger (27) as creating a "symbiosis of different perspectives" which was never "settled". Was the experience of patients using images in the consultation "unsettling" for clinicians?

Photographic images have multiple meanings, requiring interpretation; some photographs in the present study (Figure 1A) represented damage or threat metaphors for patients (44), although even clear representations were also interpreted metaphorically (8). An image of a flame may tell us no more than using the adjective 'burning' to describe pain, but it may elicit more sensory response in the viewer.

The study has some weaknesses. The numbers are small for a quantitative study, and participants were not randomly assigned, but rather were allocated effectively by time of referral. Furthermore, a substantial minority of patients may not find images helpful; however, in the project they were allocated by time of referral and not by preference. The rating scales completed by patients and clinicians are of low sensitivity; generally, high ratings by patients across consultations further reduced sensitivity. Patients may have felt an expectation to evaluate use of images positively. Participating clinicians were, to an extent, self-selected, with a higher likelihood of participation from more experienced clinicians who were accustomed to discussing emotional concerns with patients. However, self-selection did not mean that all were enthusiasts for the method, and one was quite open about his scepticism, modified after the experience. While fewer clinicians may have reduced variance attributable to them, it could instead have introduced distinct biases.

The study also had some notable strengths, in particular its full involvement of patients and of an experienced artist in creating the images in an iterative process that has produced striking and communicative artwork $(24,25)$. Patients had no difficulty choosing images that they found personally meaningful to share with clinicians, effectively validating their experience of pain (45). Photography creates a distance between the experience photographed and the emotions elicited in the viewer, perhaps allowing difficult feelings to be discussed $(27,29)$. Photographs require interpretation, necessitating negotiation of a shared understanding; thus, material may have been

\section{REFERENCES}

1. Deignan A, Littlemore J, Semino E, eds. Figurative language, genre and register. Cambridge: Cambridge University Press 2013;267-304.

2. Padfield D. Perceptions of Pain, 1st edn. Stockport: Dewi Lewis Publishing, 2003.

3. Main S. Picturing pain: Using creative methods to communicate the experience of chronic pain. Pain News 2014;12:32-5.

4. Loeser J. Pain, suffering, and the brain: A narrative of meanings. In: Carr D, Loeser J, Morris D, eds. Narrative Pain and Suffering: Progress in Pain Research and Management, Volume 34. Seattle: IASP Press, 2005:17-27.

5. Bourke J. The Story of Pain: From Prayer to Painkillers. Oxford: Oxford University Press, 2014

6. Kenny DT. Constructions of chronic pain in doctor-patient relationships: Bridging the communication chasm. Patient Ed Counseling 2004;52:297-305.

7. Scarry E. The body in pain: The making and unmaking of the world. Oxford: Oxford University Press, 1985.

8. Biro D. The Language of Pain. Finding words, compassion and relief. New York: WW Norton \& Co, 2010.

9. Bourke J. Pain and the politics of sympathy, historical reflections, 1760s to 1960s (Utrecht: Universiteit Utrecht). Back to Context 2011:10.

10. Davis FD. The problem of pain. In: Giordano J, ed. Maldynia, Multidisciplinary Perspectives on the Illness of Chronic Pain. New York: Taylor \& Francis, 2011:243-55. elicited that would not otherwise have been shared. For example, one card (Figure $1 \mathrm{E}$ ) shows a chain with one link missing, originally a visualization of back pain, but in the consultation drew from the patient who chose it a moving account of the 'gap' left by her family deciding not to visit her at Christmas, her first mention of this major source of distress. Patients' comments in free text confirmed that use of images had encouraged their disclosure of emotional aspects of their pain. The study was nondirective with patients regarding how images were to be used in the consultation, and the consultations were genuine, with the superordinate requirement that the patient was adequately assessed.

It is difficult to assess the impact images had on the pain consultation by self-report and quantitative methods alone $(37,46)$. We are keen to see replications using better scales to sample patient and clinician experience, and perhaps to permit self-selection of patients into the study according to their enthusiasm for visual means of communicating pain. However, it may be that quantitative methods cannot be applied to the use of images in this way, and that a unifying conceptual framework of narrative and image is needed (47). Pain experience is a particularly worthwhile area in which to address the challenges of capturing narratives of health and illness (30). While patients' and clinicians' quantitative evaluations did not reveal differences in experience of consultation using images, the large majority of both patients and clinicians reported that the photographic images facilitated the consultation; thus, our findings should not discourage further investigation.

ACKNOWLEDGEMENTS: This work was completed as part of Deborah Padfield's PhD thesis under the primary supervision of Professor Sharon Morris, Slade Deputy Director, Slade School of Fine Art, London, United Kingdom. Her PhD was funded by the Arts and Humanities Research Council UK. The authors are grateful to all the patients and clinicians who participated in the study.

DISCLOSURES: None of the authors has any conflict of interest to declare.

FINANCIAL SUPPORT: Funding: Arts \& Humanities Research Council and Arts Council England. Deborah Padfield was supported by the Arts \& Humanities Research Council and Joanna Zakrzewska was supported by the National Institute for Health Research University College London Hospitals Biomedical Research Centre while performing this research.

11. Broadbent E. Niederhoffer K, Hague T, et al. Headache sufferers' drawings reflect distress, disability and illness perceptions. J Psychosom Res 2009;66:465-70.

12. Uden A, Astrom M, Bergenudd H. Pain drawings in chronic back pain. Spine 1988;1394:389-92.

13. Wilkinson M, Robinson D. Migraine art. Cephalalgia 1985;5:151-7.

14. Wikstrom BM. Health professionals' experience of paintings as a conversation instrument: A communication strategy at a nursing home in Sweden. Applied Nurs Res 2003;16:184-8.

15. Maclean S. Exploring the use of drawings for patients communicating chronic pain to healthcare professionals. Pain News 2009;34-37.

16. Collen M. Life of pain, life of pleasure: Pain from the patients' perspective - the evolution of the PAIN exhibit. J Pain Palliat Care Pharmacotherapy 2005;19:45-52.

17. Collen M. PAIN <http://painexhibit.org/> (Accessed August 5, 2014).

18. Geller, B. The PainT project. Pain News 2011;42-3.

19. Padfield D, Janmohamed F, Zakrzewska J, et al. A slippery surface, can photographic images of pain improve communication in pain consultations? Internat J Surg 2010;8:144-50.

20. Carlin N, Cole T. Maldynia as muse: A recent experiment in the visual arts and medical humanities. In: Giordano J, ed. Maldynia: Multidisciplinary Perspectives on the Illness of Chronic Pain. New York: Taylor \& Francis, 2011:103-22.

21. Bolton G. Book review: Perceptions of Pain. Brit J Gen Pract 2004;54:77. 
22. Emery A. Book Review: Perceptions of Pain. Clin Med 2003;3:590.

23. Munro R. Exhibition Review. Beyond Words. Nurs Times 2002;98:12.

24. Vass A. Exhibition review: Finding a visual language for pain. Brit Med J 2002;324:1162

25. Wildgoose J. Exhibition Review. Seeing is believing: Finding a visual language for pain. Lancet 2002;359:1786.

26. Padfield D. Mask:Mirror:Membrane. Pain News (British Pain Society) 2012;10:104-9.

27. Berger J. Ways of seeing. London: Penguin. 1972

28. Burgin V. Photographic practice and art theory. In Burgin V, editor. Thinking Photography. Basingstoke: Palgrave Macmillan, 1982:39-83.

29. Sontag S. Regarding the pain of others. London: Hamish Hamilton, 2003

30. Harrison B. Seeing health and illness worlds - using visual methodologies in a sociology of health and illness: A methodological review. Sociol Health Illness 2002;24:856-72.

31. Schatman ME. Psychological assessment of maldynic pain; the need for a phenomenological approach. In: Giordano J, ed. Maldynia: Multidisciplinary Perspectives on the Illness of Chronic Pain. New York: Taylor \& Francis, 2011:157-82.

32. Padfield D. Representing the pain of others. Health 2011;15:241-57.

33. Padfield D. Believing is seeing. Clin Med 2002;2:571-2.

34. Padfield D. MASK: MIRROR: MEMBRANE. The photograph as a mediating space in clinical and creative pain encounters. PhD dissertation. London: University College London, 2013.

35. Bleakley A, Bligh J, Browne J. Medical education for the future: Identity, power and location. Advances in Medical Education. New York: Springer, 2011.
36. Green CR. Being present: The role of narrative medicine in reducing the unequal burden of pain. Pain 2011;152:965-6.

37. Shaw SE, Bailey J. Discourse analysis: What is it and why is it relevant to family practice? Fam Pract 2009;26:413-19.

38. Dworkin RH, Turk DC, Farrar JT, et al. Core outcome measures for chronic pain clinical trials: IMMPACT recommendations. Pain 2005;113:9-19.

39. Engel GL. The need for a new medical model: A challenge for biomedicine. Science 1977;196:129-36.

40. Greenhalgh T, Hurwitz B. Narrative based medicine: Dialogue and discourse in clinical practice. London: BMJ Publications, 1998.

41. Hurwitz B. Narrative and the practice of medicine. Lancet 2000;356:2086-9.

42. Hurwitz B, Charon R. A narrative future for healthcare. Lancet 2013;381:1886-7.

43. Turk DC, Dworkin RH, Burke LB, et al. Developing patient-reported outcome measures for pain clinical trials: IMMPACT recommendations. Pain 2006;125:208-15.

44. Aldrich S, Eccleston C. Making sense of everyday pain. Soc Sci Med 2000;50:1631-41.

45. Davey B, Seale C. Experiencing and Explaining Disease, 3rd edn. Buckingham: Open University Press, 2002.

46. Britten N. Qualitative interviews in medical research. Brit Med J 1995;311:251-3.

47. Radley A. Works of illness: Narrative, picturing and the social response to serious disease. Ashby-de-la-Zouch, United Kingdom: InkerMen Press, 2009. 


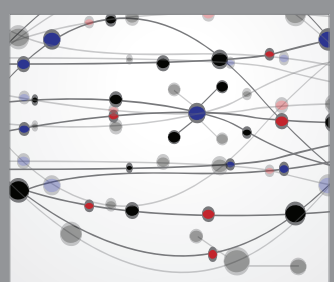

The Scientific World Journal
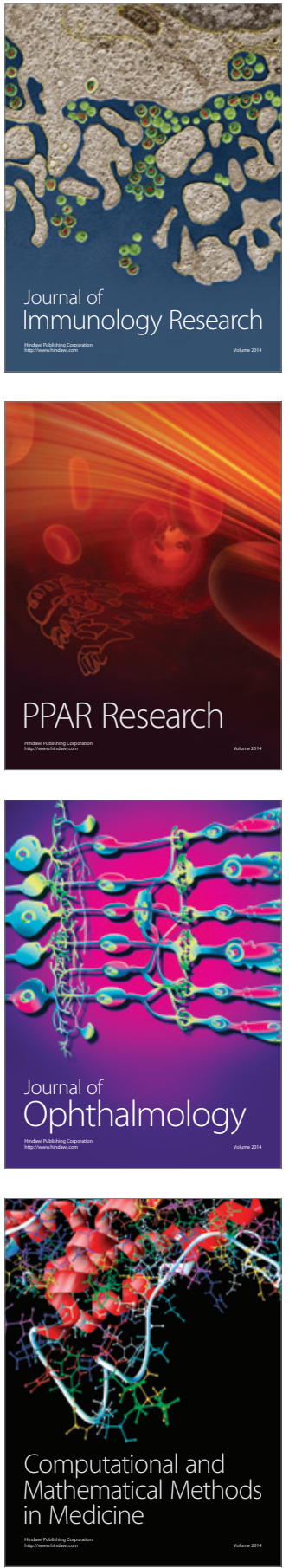

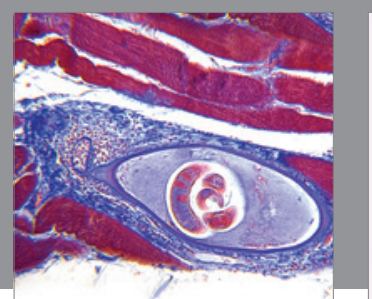

Gastroenterology Research and Practice

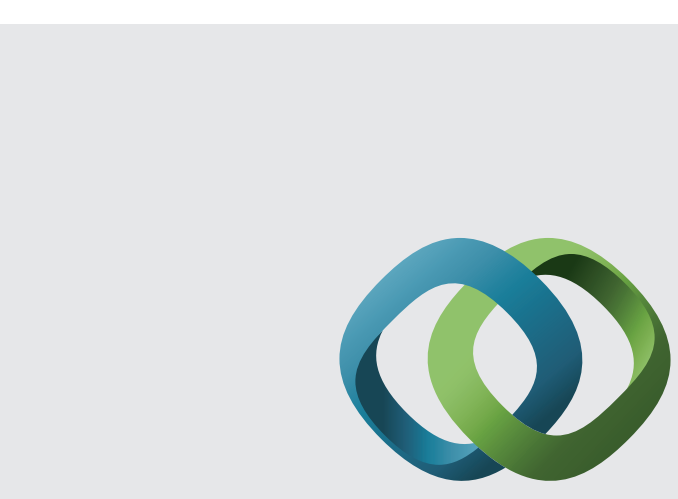

\section{Hindawi}

Submit your manuscripts at

http://www.hindawi.com
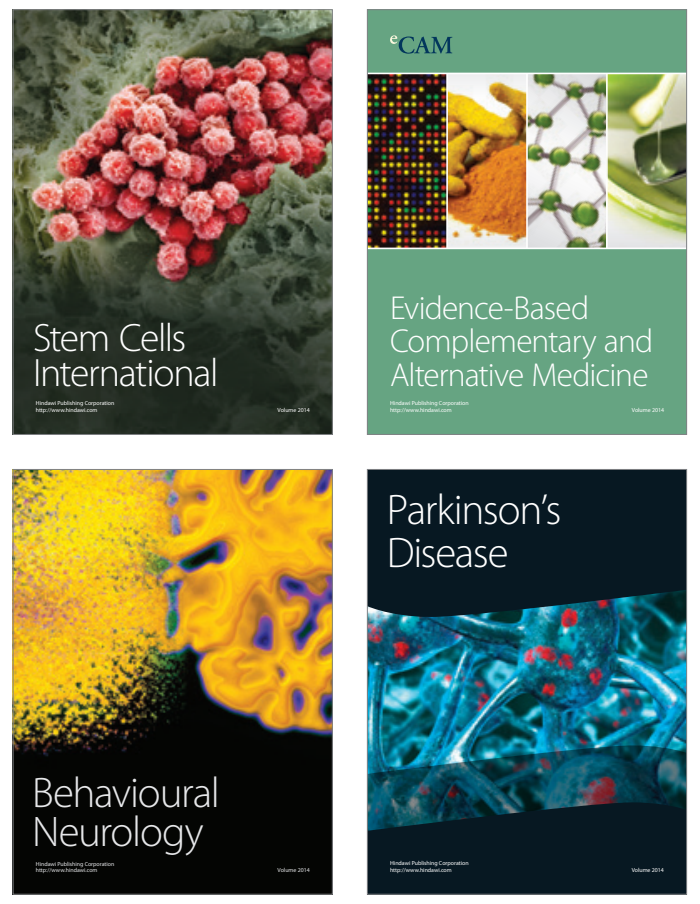
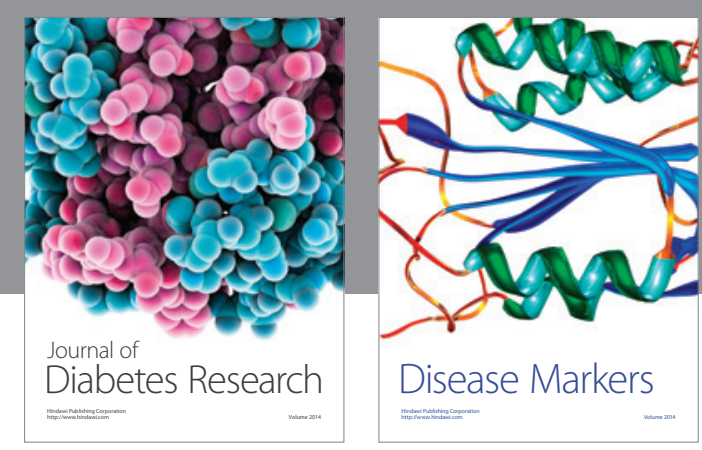

Disease Markers
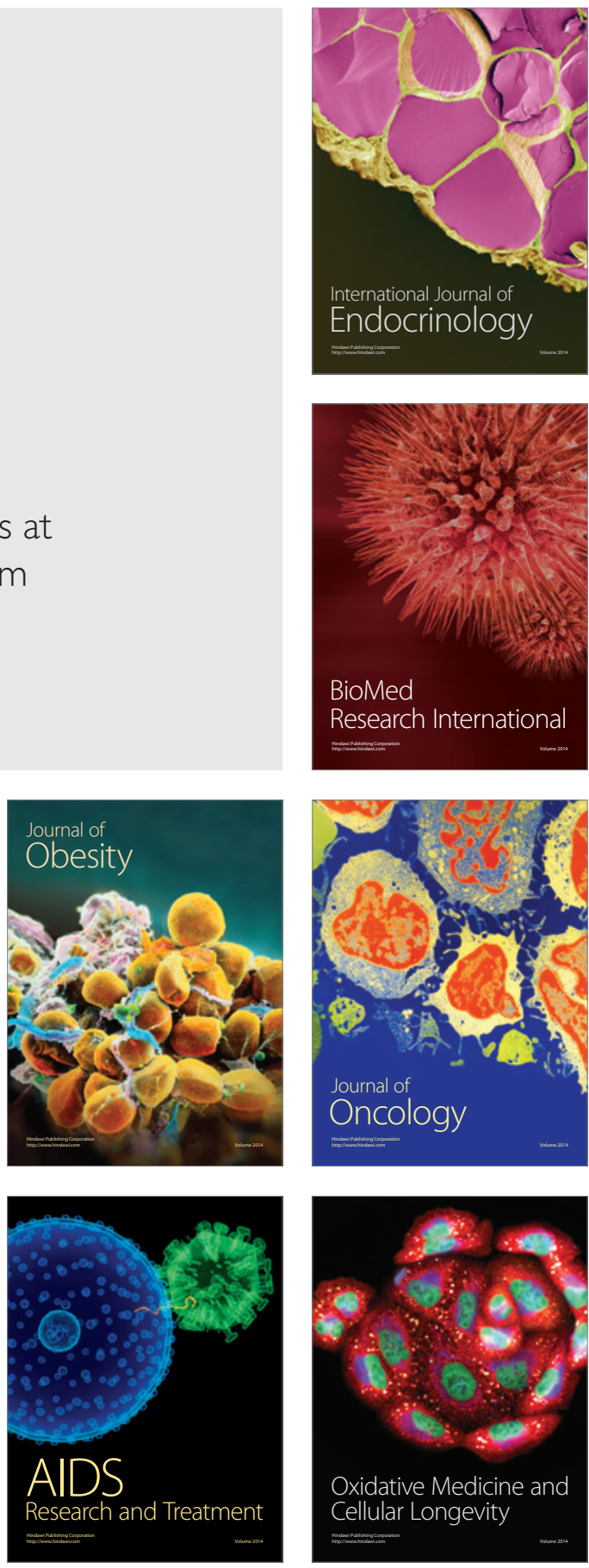